\title{
Carta do Dr. Gilles Gachet, Presidente do Club-mousse.com
}

The foam club was born in 2005 in France of the willingness of some vascular doctors pioneers in endovenous treatment of varicose veins with foam. They felt the need to benefit from the experience accumulated by comparing their respective practices. At a rate of 4 meetings per year, all of the technical issues have been addressed. Naturally has imposed the need to write the results of this work. Thus was born in 2007 in Grenoble consensus which 2012 updated version is available on the club website foam: la-mousse.com in 6 languishes. You can download, including the consent form for your patients.

This consensus is based on international studies that demonstrate the efficacy and safety of this treatment. He was subjected to readers: academics, vascular surgeons, general practitioners, patients gathered in associations and updated according to the evolution of the technique and the results of scientific studies. Members of the Steering Group have volunteered to work and say they have no financial relationship with industry domain. It contains the following chapters: the history, training, equipment, clothing foam, indications / cons-indications, echo-Doppler examination, injection controls after treatment, complications and safety reporting and regulatory aspects and finally the patient information. It is updated each year based on technical progress (the 2008 version and the second). He has been featured in numerous international conferences and will soon be translated into English and German. Drafting the consensus is not the only task of the CLUB MOUSSE (foam club), he participated in scientific studies as CLASSMOUSS and organizes training sessions either by itself or in national and international conferences (SFP ARMV, SFMV ...). It also defends the practice of foam appears disturbed by his growing success (the foam treatment is now widespread throughout France). Forming the vascular physicians willing to treat varicose veins with foam, the club hopes to minimize accidents often caused by a wrong practice (standardization is the goal to formalize the technique) because, as shown by scientific studies, technique is probably the safest and most effective way to treat varicose veins.

Docteur Gilles GACHET

Voiron - França.

www.club-mousse.com

giga1@orange.fr

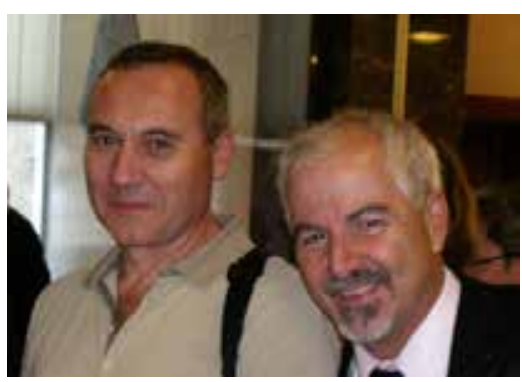

